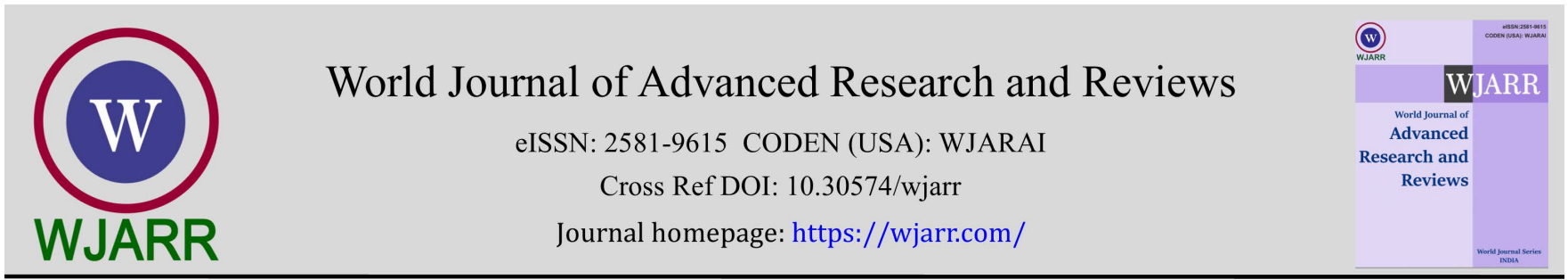

(RESEARCH ARTicle)

Check for updates

\title{
Preparation and characterization of CdS thin film using chemical bath deposition (CBD) technique for solar cell application
}

\author{
F.T.Z. Toma ${ }^{1,}{ }^{*}$, K.M.A. Hussain ${ }^{1}$, M.S. Rahman ${ }^{2}$ and Syed Ahmed ${ }^{1}$ \\ ${ }^{1}$ Experimental Physics Division, Atomic Energy Centre, 4-Kazi Nazrul Islam Avenue, Shahbag, Dhaka-1000, Bangladesh \\ Atomic Energy Commission, Bangladesh. \\ 2 Electrical and Electronic Engineering Department, Technical Teachers' Training College, Tejgaon Industrial Area, \\ Dhaka-1208, Bangladesh.
}

World Journal of Advanced Research and Reviews, 2021, 12(03), 629-633

Publication history: Received on 25 November 2021; revised on 28 December 2021; accepted on 30 December 2021

Article DOI: https://doi.org/10.30574/wjarr.2021.12.3.0746

\begin{abstract}
The structural properties of CBD deposited CdS thin films have been studied by varying the processing parameters and $\mathrm{Cd} / \mathrm{S}$ ratio of the starting Precursors in order to better understand the growth conditions. A CdS thin film was prepared on glass substrate by CBD method from a bath containing Thiourea and Ammonium hydroxide. The structural analysis was performed by X-ray Diffraction (XRD). The deposited CdS thin film was a cubic phase with small nano crystalline grains. The film was deposited at $60^{\circ} \mathrm{C}$ for 2 hours. After sintering the film at $300^{\circ} \mathrm{C}$ for 1 hour the color of the film was changed like dark yellowish and the thickness of the film was obtained $100 \mathrm{~nm}$. The FTIR was done at room temperature over $350 \mathrm{~cm}^{-1}$ to $4500 \mathrm{~cm}^{-1}$ and it showed the existence of different functional group in the sample and their probable source. These studies have allowed us to establish a standard set of conditions for the fabrication of homogeneous and continuous very thin $\mathrm{CdS}$ films in laboratory and this preparation technique is also suitable for preparing highly efficient thin film due to its advantages such as simple, large area films, low deposition temperature and low-cost method.
\end{abstract}

Keywords: CBD; XRD; Sintering Temperature; XRD; FTIR etc

\section{Introduction}

CdS thin films are regularly fabricated using different synthesis methods because of its vast area of application. Mainly, CdS thin films are widely used as absorber and optical conductor of window solar cell. In this research work, we mainly focus on n-type CdS thin films synthesized by Chemical bath deposition method [1, 2]. In recent years, CdS thin films have been fabricated using different methods such as spray pyrolysis, electrochemical deposition, molecular beam deposition, laser ablation, chemical bath deposition and SILAR method [3-8]. All these methods require sophisticated instruments and which are very costly. Among all the thin film deposition techniques, chemical bath deposition (CBD) is the simplest one that has great scope for large area fabrication [9-12]. The CBD technique has been used for many years to prepare thin films of chalcogenide semiconductors and other kind of materials. CBD techniques can be used to deposit uniform thin films over large area having complex geometries. It is easy to handle and capable of yielding good quality thin films. This technique has been extensively used for the preparation of CdS thin films because of its application as a window layer material in solar cell fabrication. The purpose of this research work is to prepared chemically deposited CdS thin film on glass substrate as low cost and easy method using CBD technique.

\footnotetext{
${ }^{*}$ Corresponding author: F.T.Z. Toma

Scientific Officer, Experimental Physics Division, Atomic Energy Centre, 4-Kazi Nazrul Islam Avenue, Shahbag, Dhaka- 1000, Bangladesh Atomic Energy Commission, Bangladesh.

Copyright (C) 2021 Author(s) retain the copyright of this article. This article is published under the terms of the Creative Commons Attribution Liscense 4.0.
} 


\section{Experimental details}

\subsection{Substrate Preparation}

Substrate preparation is very important part in the deposition of thin films. In principle, most clean surfaces can be used as substrates, although the degree of adhesion can vary greatly from one material to another. Glass is one of the most commonly used substrates in Chemical Bath Deposition (CBD). In spite of the fact that glass is a relatively inert material, the surface of glass can be very reactive towards species in solution. Procedure for cleaning the substrate is important, as it is one of the factors determining the composition and grain size of the film. There are various cleaning methods depending on the nature of the substrate, type of contaminants and the extent of cleanliness required for thin film deposition. Substrate preparation basically includes cutting of the substrate into fixed pieces and cleaning substrate. For this experiment Soda lime glass substrate has been used. The glass substrate was cut from large glass slide into a desired dimension of $3.7 \mathrm{~cm} \times 2.5 \mathrm{~cm}$. After substrate was selected it was prepared for the experiment by "Etching Bath Process". The glass substrate was cleaned by a number of processes. In the first step, the glass substrate was scrubbed for 2-3 minutes with acetone and then cleaned with glass cleaner. In the next step, the substrate was submerged in soap water for 24 hours. Then the substrate was washed with water for 1 hour using hands. Then it was kept under continuous water flow for another 30 minutes. Then the substrate was immersed in a beaker and again cleaned with water. Next the substrate was immersed in a beaker containing ethanol and the beaker was treated in an etching bath for 40 minutes. After the bath, the samples were dried with a dry pump. The substrate was then put in an oven and heated at $100^{\circ} \mathrm{C}$ for 1 hour for further drying. Acetone was used for removing organic impurities from the glass substrates, particularly for dissolving oily or greasy contaminants. However, acetone evaporates rapidly and will redeposit the contaminants. So, Ethanol was used that works very well to dissolve the acetone with its contaminants, without rapidly evaporating.

\subsection{Synthesis of CdS thin Film}

The preparation conditions of CdS thin films were optimized by adjusting concentration of dissolved chemicals, bath temperature, and bath solution $\mathrm{pH}$ as well as deposition time to obtain homogeneous films with good adherence to the substrate. The figure of the deposition technique is given bellow.

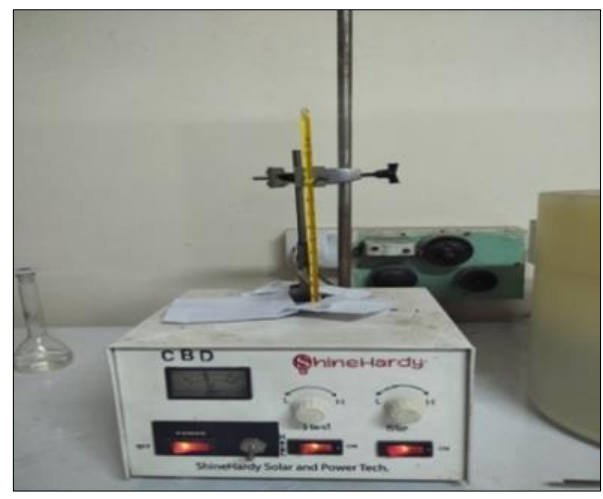

Figure 1 Chemical Bath Deposition System

Table 1 Chemical components for depositing CdS thin film

\begin{tabular}{|c|l|}
\hline No & \multicolumn{1}{|c|}{ Chemical Components } \\
\hline 1 & Cadmium Cloride $\left(\mathrm{CdCl}_{2}\right)$ \\
\hline 2 & Ammonia Water $\left(\mathrm{NH}_{4} \mathrm{OH}\right)$ \\
\hline 3 & Thiourea $\left(\mathrm{CS}(\mathrm{NH})_{2}\right.$ \\
\hline 4 & Distilled water \\
\hline
\end{tabular}

The chemical bath deposition technique was used to deposit CdS thin film. In this experiment Reagents used for the deposition include cadmium Cloride $\mathrm{CdCl}_{2}$, ammonium water $\mathrm{NH}_{4} \mathrm{OH}$ and Thiourea (CS(NH) 2 . Drop by and by $25 \%$ $\mathrm{NH}_{4} \mathrm{OH}$ into a $100 \mathrm{ml}$ beaker containing $25 \mathrm{ml}$ of $1 \mathrm{M} \mathrm{CdCl}_{2}$ solution until the initially formed white precipitate in completely dissolved. $25 \mathrm{ml}$ of $1 \mathrm{M} \mathrm{CS}(\mathrm{NH})_{2}$ then is poured into the mixtures. Finally, the distilled water was gradually added to make the volume up to $100 \mathrm{ml}$. The deposition is made at $60^{\circ} \mathrm{C}$ under magnetic stirring for the sample. The 
deposition time is chosen for 2 hours. Finally, the thin film sintered at $300^{\circ} \mathrm{C}$ for 1 hour. Block Diagram for CdS Thin Film is given below.

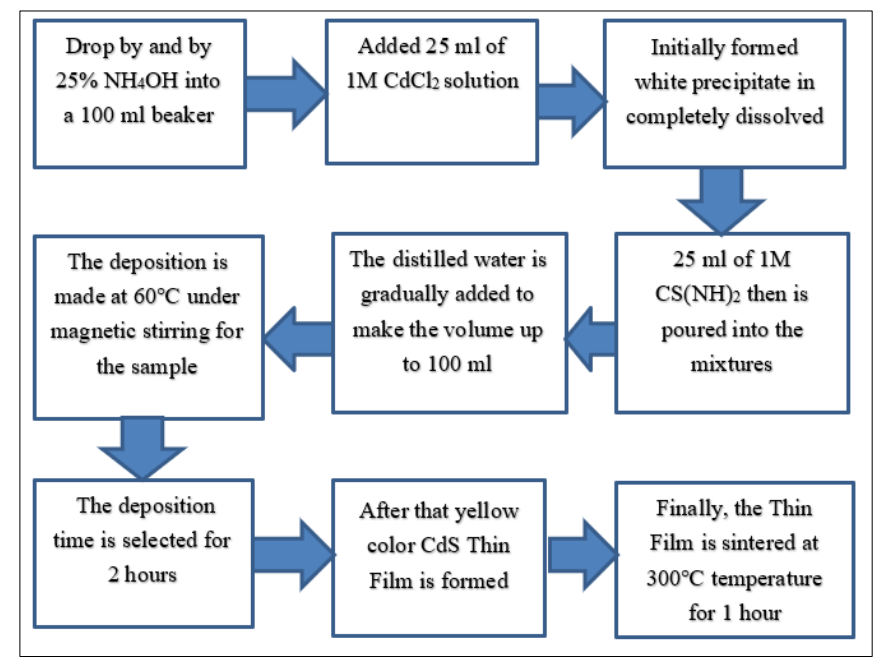

Figure 2 Block Diagram for CdS Thin Film

\section{Results and discussion}

\subsection{X-ray diffraction (XRD) Analysis}

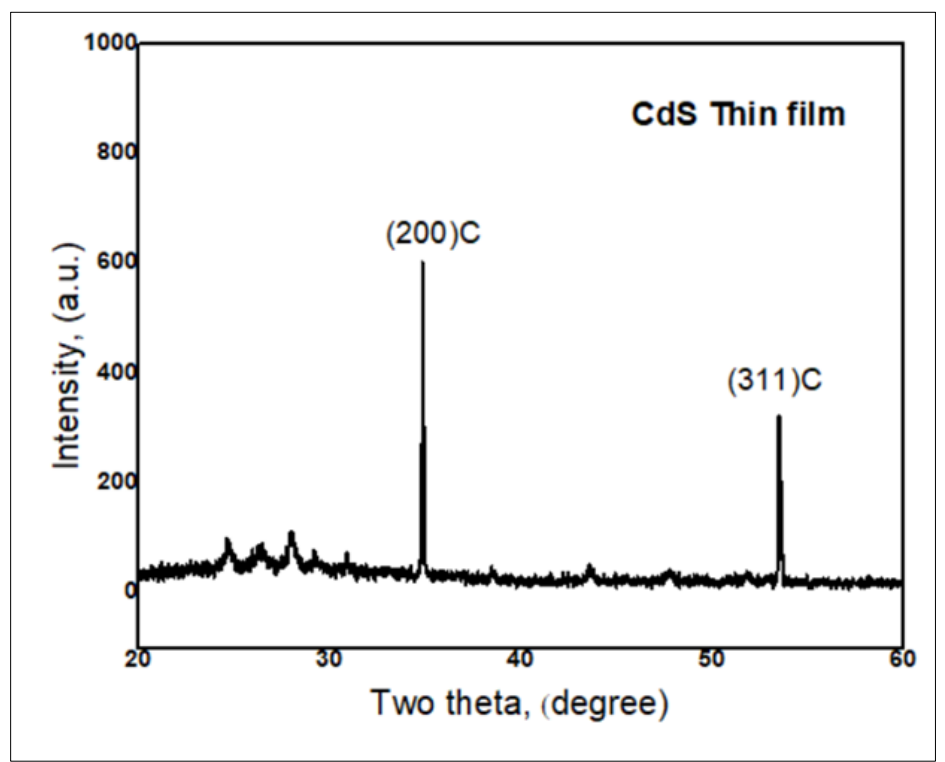

Figure 3 X-ray diffraction pattern of cadmium sulfide (CdS) Thin film

Table 2 X-ray diffraction data of CdS thin film [13]

\begin{tabular}{|c|c|c|c|c|}
\hline $\begin{array}{c}2 \theta \text { (observed) CdS thin film } \\
\text { Sample }\end{array}$ & (hkl) & d-spacing [̊̊] & FWHM [ ${ }^{\circ}$ 2Th.] & $\begin{array}{c}\text { Rel. Int. } \\
{[\%]}\end{array}$ \\
\hline 34.87 & 200 & 2.33524 & 0.0480 & 2.09 \\
\hline 53.51 & 311 & 1.71118 & 0.0720 & 36.24 \\
\hline
\end{tabular}


X-ray diffraction of CdS thin film was done by a two cycle(2Ө- $\theta$ ) X-ray powder diffractometer, X'Pert PRO XRD PW 3040 with high temperature attachment up to $1600^{\circ} \mathrm{C}$ at Magnetic Materials Division (MMD) of Atomic Energy Centre, Dhaka (AECD). It contains "Cu-tube" with maximum input power of $60 \mathrm{kV}$ and 55mA. Fig.3 shows the typical XRD pattern of asgrown CdS film on soda lime glass. The values of diffraction peaks observed are 34.87 and 53.18; these correspond [13] to reflections from (200), and (311) planes of cubic (zincblende). Intensity of the sharp peaks indicate that the sample is highly crystalline.

\subsection{Fourier-Transform Infrared Spectroscopy (FTIR)}

The FTIR spectrum of the cadmium sulfide thin film is shown in the figure 4. The FTIR spectrum for cadmium sulfide film shows peak at $3439.18 \mathrm{~cm}^{-1}$ corresponds to the free $0-\mathrm{H}$ group and the peak at $1611.91 \mathrm{~cm}^{-1}$ is due to the presence of hydroxyl group of water C-H bond and the peak at $1082.44 \mathrm{~cm}^{-1}$ corresponds to S-O bond and $665.83 \mathrm{~cm}^{-1}$ is due to $\mathrm{S}-\mathrm{S}$ bond. The peak at $466.40 \mathrm{~cm}^{-1}$ responds to $\mathrm{Cd}-\mathrm{S}$ bond [14].

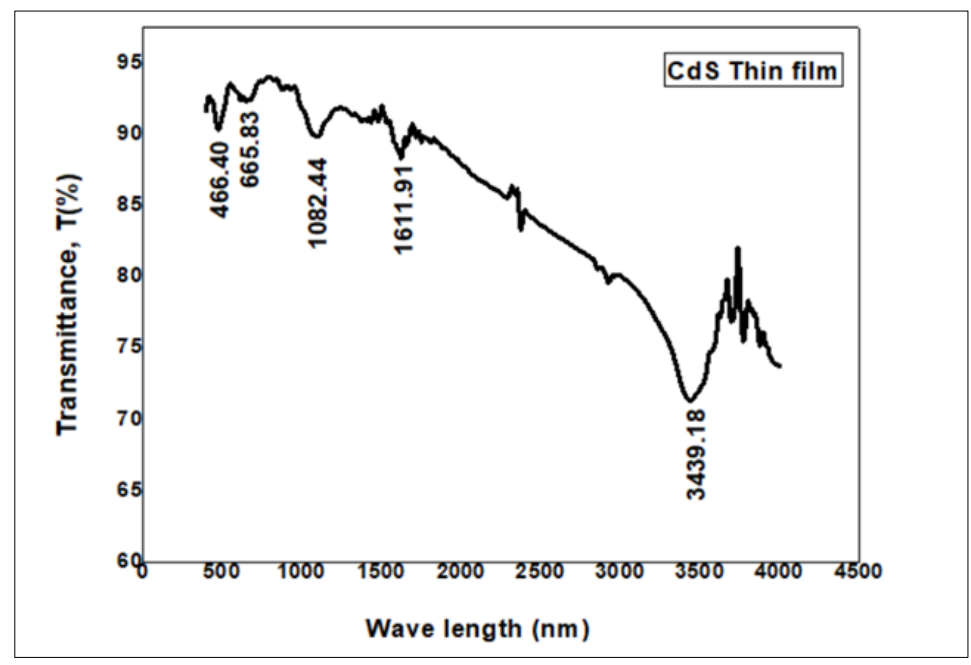

Figure 4 FTIR spectra of cadmium sulfide (CdS) Thin film

Table 3 Interpretation of the peaks obtained by the FTIR Spectra of the synthesized CdS thin film [15]

\begin{tabular}{|c|c|l|l|}
\hline Peak & Region & \multicolumn{1}{c|}{ Intensity } & \multicolumn{1}{c|}{ Interpretation } \\
\hline $\mathrm{a}$ & $400-480$ & Sharp and strong & Cd-S bond stretching (CdS nanoparticles) \\
\hline $\mathrm{b}$ & $650-850$ & Small and weak & S-S-S bending or C-H stretching (crystal s-s-s bond or acetone) \\
\hline $\mathrm{C}$ & $1060-1120$ & Broad and small & C-O or S-O (acetone or sulphate \\
\hline $\mathrm{d}$ & $1380-1640$ & Sharp and small & C-H bending of $\mathrm{CH}_{3}$ (Acetone) \\
\hline $\mathrm{e}$ & $3140-3460$ & Sharp and strong & Intermolecular H-bonds (Lattice water) \\
\hline
\end{tabular}

\section{Conclusion}

This study elucidates the step by step procedure of the preparation of pure CdS thin films by chemical bath deposition method. Although Chemical Bath Deposition method is the simplest of all, deposition parameter optimization is needed for good quality sample. The CdS thin film is a potential candidate used in various application like solar cells. Single phase CdS confirmed by XRD. XRD spectra confirmed the Cubic structure of the prepared sample with a preferred orientation along 200 planes. X-ray diffraction results have further confirmed that CdS film grown by CBD in a basic aqueous bath independent of the growth process in an almost homogeneous free reaction bath has a cubic structure. The FTIR analysis shows the presence of different functional group in the sample. Thus, the present method is a simple and efficient for the preparation of nano-crystalline CdS thin film at low deposition temperature with excellent structural and elemental properties which could find their applications in optoelectronic devices, light emitting diodes and also to be used as a window layer for solar cell applications. 


\section{Compliance with ethical standards}

\section{Acknowledgments}

The authors would like to express their sincere gratitude to the organization of Materials Science Division, Atomic Energy Centre, Dhaka, BAEC for the XRD and FTIR measurements and also thanks to the division of Experimental Physics Division, AECD, Bangladesh Atomic Energy Commission for providing the Deposition system.

\section{Disclosure of conflict of interest}

The authors declare that there is no conflict of interests regarding the publication of this paper.

\section{References}

[1] W Wang, I. Germanenko, M Samy El-Shall. Room-Temperature Synthesis and Characterization of Nanocrystalline CdS, ZnS, and CdxZn1-xS. Chem. Mater. 2002; 14: 3028.

[2] Zhang Weiguang, Zhong Yun, Fan Jun, Sun Siqiao, Tang Ning, Tan Minyu, Wu Longmin. S Structural and optical characterization of CdS nanoparticles synthesized using a simple chemical reaction route. Science in China. 2003; 46: 196.

[3] RS Mane, CD Lokhande. Chemical Deposition Method for Metal Chalcogenide Thin Films. Mater. Chem. Phys. 2000; 65: 31.

[4] Yanbao Zhao, Zhijun Zhang, Hongxin Dang, Weimin Liu. Synthesis of tin sulfide nanoparticles by a modified solution dispersion method. Materials Science and Engineering B. 2004; 113(2): 175-178.

[5] M Maleki, M Sasani Ghamsari, Sh Mirdamadi, R Ghasemzadeh. A facile route for preparation of CdS nanoparticles. Semiconductor Physics, Quantum Electronics \& Optoelectronics. 2007; 10(1): 30-32.

[6] R Ellilarassi, S Maheshwari, G Chanarasekaran. Structural and optical characterization of CdS nanoparticles synthesized using a simple chemical reaction route. Optoelectronics and Advanced Materials- Rapid Communications. March 2010; 4: 3309 - 312.

[7] AA Yadav, MA Barote, EU Masumdar. Photoelectrochemical properties of spray deposited n-CdSe thin films. Solar Energy. 2010; 8: 763.

[8] Smt Swapna Samanta, MS Shinde, RS Patil. Synthesis and Characterization of Cadmium Selenide Nanocrystalline Thin Films Prepared Using Novel Chemical Approach. J. Nano. Adv. Mat. 2016; 4(2): 53-57.

[9] G Perna, V Capozzi, M Ambrico. Structural properties and photoluminescence study of CdSe/Si epilayers deposited by laser ablation. J. Appl. Phys. 1998; 83: 33-37.

[10] Nitya Garg. Brief Review on Synthesis of CdSe Nanomaterials. Journal of Nanoscience Nanoengineering and Applications. 2018; 7: 3.

[11] FTZ Toma, MS Rahman, KMA Hussain, H Das, MNI Khan. Effect of the Annealing Temperature on CdS Nanoparticles Synthesized by Chemical Precipitation Technique and also Characterized for its Potential Technological Applications. Nano Trends: A Journal of Nanotechnology and Its Applications. 2021; 23(3): 20-27.

[12] Hullavarad NV, Hullavarad SS, Karulkar PC. Cadmium Sulphide (CdS) Nanotechnology: Synthesis and Applications. Journal of Nanoscience and Nanotechnology. 2008; 7(28): 3272-3299.

[13] Iesaish lee chow, JR Liu. Comparative study of CdS thin films deposited by single, continuous, and multiple dip chemical processes. Thin Solid Films. 2000; 359(2): 154-159.

[14] R. Hepzi Pramila Devamani, R Kiruthika, P Mahadevi, S Sagithapriya. Synthesis and Characterization of Cadmium Sulfide Nanoparticles. IJISET - International Journal of Innovative Science, Engineering \& Technology. January 2017; 4(1): 2348 - 7968.

[15] N Qutub, S Sabir. Optical, Thermal and Structural Properties of CdS Quantum Dots Synthesized by A Simple Chemical Route. Int. J. Nanosci. Nanotechnol. June 2012; 8(2): 111-120. 